\title{
Effect of superior-subordinate Guanxi on job performance in China
}

\author{
Xiao-qiang Ma , Jie Liu * \\ School of Economics \& Management Northwest University, Xi'an China \\ *Corresponding author: Jie-Liu, Master Degree, liujie.nwu@qq.com
}

\begin{abstract}
In this article, 327 employees were chosen as the sample and tested using hierarchical regression, in order to examine the impact of the SSG orientated subordinate relationship to their job performance, as well as to analyze what difference proactive personality will make. Conclusions can be drawn from the results as follows: first, among the three dimensions of superior-subordinate guanxi, deference to supervisor and emotional attachment has a significant correlation with job performance, whereas personal-life inclusion proved to be of no significant correlation; there are strong correlation between overall superior-subordinate guanxi variables and job performance; second, the proactive personality moderates the connection between subordinate relationship and job performance to some extent.
\end{abstract}

Key words: superior-subordinate Guanxi; job performance; proactive personality; moderation effect; hierarchical regression

\section{Introduction}

Traditional organization research usually ignores the effect of informal relationship on the job performance. Nowadays, with the ever-growing economic globalization, enterprises in the constant adjustment and upgrading the industrial structure, the organization's operation philosophy has changed, the view of "superior-subordinate relationship has become the key to the operation of the organization" has already become a consensus. 1 For instance, subordinates' job performance, job satisfaction and turnover intention are affected by the relationship between the superior and the subordinate. China plays an important role in the world economy, more and more academics are working in accordance with the current situation in China hierarchy theory to study how superior-subordinate guanxi affects employees' work attitude and behaviour.

Proactive personality refers to the tendency of individuals to be able to positively influence their environment without situational resistance. ${ }^{2}$ Study confirms that proactive personality for many individuals and organizations has positive influence in terms of team performance, job performance, career success, entrepreneurship. ${ }^{3}$ However, current studies regarding the relationship between superior-subordinate guanxi and work performance rarely research the role of proactive personality. In light of this, this paper will study whether, under the background of Chinese society and culture, staff with highly proactive personality will 
develop informal relationships with leadership in assistance to achieve a better job performance.

\section{Literature review and research hypotheses}

The Supervisor - Subordinate Guanxi construct (SSG) in Chinese situation is similar to the leader member exchange (LMX) in western literature. LMX comes from the work-related interaction development, which reflects the quality of the work relation between leaders and subordinates; while the SSG in Chinese situation refers to the interpersonal relationship between leaders and subordinates, which based on the human joint of the human law. ${ }^{4,5}$ However the LMX theory is not appropriate in explaining the superior-subordinate guanxi in Chinese situation, hence some scholars devoted to the empirical study on the SSG construct in Chinese situation. The type division of the SSG construct in this article refers to the SSG $3 \mathrm{~d}$ model proposed by Chen, Friedman \& Yu et al. (2009), it was divided into three dimensions as obedience leadership, emotional attachment and personal-life inclusion. ${ }^{6}$

Borman (1993) believed that the job performance is used to measure the work behavior of the staff through the complete degree of organizational goals, which can also be considered as a detailed description of the expectations to the employees and the aiming to encourage employees' continuous goal orientation program of the job performance. ${ }^{7}$

According to the research, harmonious SSG in the groups benefits to the employees for improving the self-assessment, increasing the sense of identity and keeping the positive work attitude and efficient work efficiency, thus improving the job performance. Graen and Cashmen's research showed that the high quality of the SSG lead to the high job performance of the employee. Based on this, we can make the following assumptions:

Hypothesis 1: Supervisor - Subordinate Guanxi is positively related to job performance.

Hypothesis 1a: Obedience leadership is positively related to job performance.

Hypothesis 1b: Emotional attachment is positively related to job performance.

Hypothesis 1c: Personal-life inclusion is positively related to job performance.

Proactive personality was put forward by Bateman and Crant in the 1990s and they claimed that proactive personality means that individual cannot be restricted by situational factors, which sustainably affected surroundings with a positive tendency. ${ }^{2}$ The related researches imply that the proactive personality plays an important role in the relationship between individual and surrounding environment. The individual with high proactive personality, in order to improve occupational efficacy, ${ }^{8}$ tend to adapt to the organizational environment better and take positive measures to cope with stress, which prompts to better understand the importance of the relationship between leader and subordinate and enhances the impact of the relationship between leader and subordinate on work performance. Thompson (2005) from the social capital perspective, held the view that individual who has the proactive personality take the initiative to improve job performance through the relationship construction. ${ }^{9}$ To sum up, as one of the individual characteristics, proactive personality is an important adjustment 
variable when leader-subordinate relationship influences work performance.

Hypothesis 2: Proactive personality plays a moderating role in the relation of SSG and job performance.

Hypothesis 2a: Proactive personality plays a moderating role in the relation of obedience leadership and job performance.

Hypothesis 2b: Proactive personality plays a moderating role in the relation of emotional attachment and job performance.

Hypothesis 2c: Proactive personality plays a moderating role in the relation of personal-life inclusion and job performance.

To sum up, this paper poses a theoretical model, as shown in the Fig. 1:

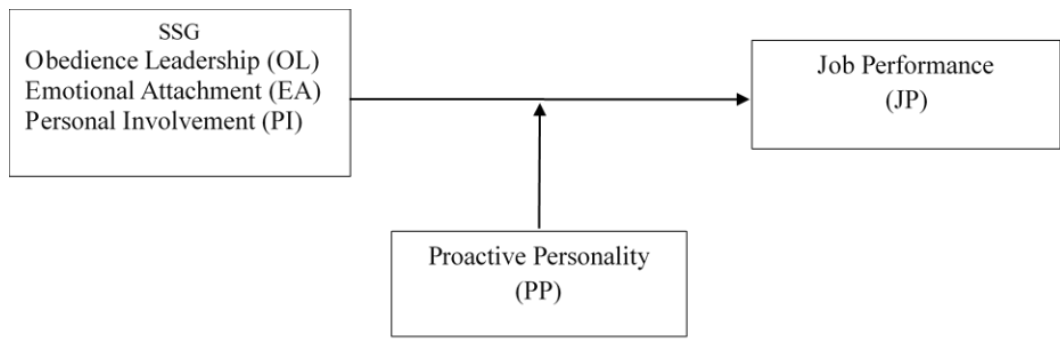

Fig.1 - Study model

\section{Data Analysis and Results}

The selection criteria of the sample enterprise in this study were: (1) established for at least one year; (2) scale in more than 30 people; (3) complete and clear organizational structure and personnel arrangements; (4) at least three employees besides managers. The selection scope is the enterprise of the private entrepreneurs and the head of the state-owned enterprises in the MBA students of a college of economics and management in shaanxi province. Under the agreement of entrepreneurs and head, seven companies meet the standards and became the investigation object, including one foreign capital enterprise, two large state-owned subsidiaries company and for private enterprises. To avoid homologous variance, the survey was processed with the leadership - employee matching form. The study distributes questionnaires to 56 department managers and 359 employees, and finally collected 327 valid questionnaires in 54 departments, 91.1\% effective. SSG scale refers to the classification standards by Chen et al. (2009), such as job performance and proactive personality scale were translated by professionals with the western mature scale, conforms to the Chinese context and three kinds of questionnaires were tested and modified during the study. The alpha coefficient and KMO coefficients of all scales are more than 0.8 , indicate a good validity.

\subsection{Correlation matrix of the variables}

Table 1 is the correlation coefficient and basic characteristics of the main variables in this study. From the table we can draw the following conclusion: the preliminary (1) relationship between the superior and the subordinate obedience leadership and emotional attachment of the 
three dimensions of job performance has significant correlation $(\mathrm{P}<0.01)$, personal-life inclusion in the job performance, there is no significant correlation relationship between higher and lower overall variables and job performance has significant correlation $(\mathrm{P}<0.01)$, suggesting that the relationship between higher and lower work performance has some correlation, preliminary illustrate some of the assumptions of H1. (2) proactive personality and job performance has significant correlation, the correlation coefficient is 0.167 , the significance level is 0.002 , which will then verify the hypothesis $\mathrm{H} 2$ provides the basis for us.

Table 1 - Standard deviation and correlation coefficients of main variables $(\mathrm{N}=327)$

\begin{tabular}{lccccccc}
\hline Variables & mean & standard deviation & OL & EA & PI & SSG & JP \\
\hline OL & 4.34 & 1.09 & 1 & $.606^{* *}$ & $.359^{* *}$ & $.787^{* *}$ & $.196^{* *}$ \\
& & & & .000 & .000 & .000 & .000 \\
EA & 4.49 & 1.027 & $.606^{* *}$ & 1 & $.563^{* *}$ & $.869^{* *}$ & $.214^{* *}$ \\
& & & .000 & & .000 & .000 & .000 \\
PI & 3.397 & 1.23 & $.359^{* *}$ & $.563^{* *}$ & 1 & $.804^{* *}$ & .020 \\
& & & .000 & .000 & & .000 & .714 \\
SSG & 4.08 & .914 & $.787^{* *}$ & $.869^{* *}$ & $.804^{* *}$ & 1 & $.167^{* *}$ \\
& & & .000 & .000 & .000 & & .002 \\
PP & \multirow{2}{*}{4.81} & .851 & $.368^{* *}$ & $.361^{* *}$ & $.244^{* *}$ & $.391^{* *}$ & $.167^{* *}$ \\
& & & .000 & .000 & .000 & .000 & .002 \\
JP & \multirow{2}{*}{.8389} & $.196^{* *}$ & $.214^{* *}$ & .020 & $.167^{* *}$ & 1 \\
& 5.007 & & .000 & .000 & .714 & .002 & \\
\hline
\end{tabular}

Notes: (1) **p<0.01, two-tailed test. (2) "OL" means " obedience leadership ", "EA" means " emotional attachment ", "PI" means " personal-life inclusion ", and " JP " means "job performance", “PP” means” proactive personality".

\subsection{The moderation of the proactive personality in the relationship between SSG and job performance.}

Table 2 - Regression analysis of job performance in SSG ( $\mathrm{N}=327)$

\begin{tabular}{|c|c|c|c|c|c|}
\hline \multirow{2}{*}{ Variables } & \multicolumn{5}{|c|}{ Job Performance } \\
\hline & Model 1 & Model 2 & Model 3 & Model 4 & Model 5 \\
\hline \multicolumn{6}{|l|}{ 1. control variable } \\
\hline Gender & .080 & .091 & .080 & .083 & .095 \\
\hline Age & -.152 & -.165 & -.143 & -.151 & -.149 \\
\hline Length of service in the enterprise & .147 & .157 & .160 & .150 & .164 \\
\hline In the current working time & $.108^{* *}$ & .116 & .098 & .104 & .095 \\
\hline The level of education & -.022 & -.002 & -.013 & -.019 & -.005 \\
\hline \multicolumn{6}{|l|}{ 2. independent variables } \\
\hline Obedience Leadership & & $.206^{* * *}$ & & & \\
\hline Emotional Attachment & & & $.216^{* * *}$ & & \\
\hline Personal Involvement & & & & .022 & \\
\hline SSG & & & & & $.174^{* *}$ \\
\hline$\overline{\mathrm{R}^{2}}$ & .129 & .270 & .335 & .029 & .258 \\
\hline$\Delta \mathrm{R}^{2}$ & .103 & $.243^{* *}$ & $.278^{*}$ & .011 & $.221^{*}$ \\
\hline F value & $1.890^{*}$ & $14.394^{* * *}$ & $15.998^{* * *}$ & .158 & $10.096^{* *}$ \\
\hline
\end{tabular}

Notes: $* * * p<0.01, * * p<0.05, * p<0.1$, two-tailed test.

From table 2 model 1, gender, age, length of service in the enterprise and the level of education the four control variables did not significantly affect job performance, only employees in the current working time has significantly effect on job performance, $(\beta=0.108$, $\mathrm{p}<0.1$ ). Model 2 can clearly see that, under the condition of considering the control variables, 
obedience leadership has a significant effect on job performance, $(\beta=0.206, \mathrm{p}<0.001)$. Showing that obedience leadership is relevant to job performance, high compliance leadership dimensions will improve employee performance. Let's say that H1a gets data support. Similarly, the model 3 shows that emotional attachment is positively correlated with performance $(\beta=0.216, \mathrm{p}<0.001)$, and obviously the H1b is assumed to be true. In model 4, personal-life inclusion has no significant impact on performance $(\mathrm{p}>0.1$ ), without a significant test, the assumption that the $\mathrm{H} 1 \mathrm{c}$ is not verified. According to the result of model 5 , SSG variable has a significant effect on job performance, and overall $(\beta=0.174, p<0.05)$ through the test of significance of SSG overall variables related to job performance is, the more harmonious relationship between higher and lower, employee job performance, the better. Let's say that $\mathrm{H} 1$ is supported by the data and is valid In view of the H2, we adopt the layered adjust the method of regression analysis, according to the variable interactive items to check whether there is the adjustment effect hypothesis. After joining interactive items, if its $\Delta \mathrm{R}^{2}$ is significant, so that the regulating effect exists. According to the model 6-2, model 7-2 and 8-2, proactive personality and obedience leadership dimensions of job performance of positive influence is more remarkable; It is also evident that proactive personality and emotional attachment work together in the workplace. Based on this, the regression analysis was put into the model 6-3, 7-3 and 8-3. See from these three models, $\mathrm{OL} * \mathrm{PP}, \mathrm{EA} * \mathrm{PP}$ 和 SSG*PP three interaction factors on the performance of regression coefficients are $0.134,0.082$ and 0.048 respectively, achieves the significance level of 0.1 ; And $\Delta \mathrm{R}^{2}$ are $0.237,0.253$ and 0.216 respectively, and the significance level of 0.1 . It's can verify $\mathrm{H} 2 \mathrm{a}, \mathrm{H} 2 \mathrm{~b}$, and $\mathrm{H} 2$. The H2c does not exist because the main effect does not exist, it assumes that the $\mathrm{H} 2 \mathrm{c}$ is not established

Table 3 - Proactive personality moderation effect test $(\mathrm{N}=327)$

\begin{tabular}{|c|c|c|c|c|c|c|c|c|c|}
\hline \multirow{2}{*}{ Variables } & \multicolumn{9}{|c|}{ Job Performance } \\
\hline & M 6-1 & M 6-2 & M 6-3 & M 7-1 & M 7-2 & M 7-3 & M 8-1 & M 8-2 & M 8-3 \\
\hline 1. control variable & & & & & & & & & \\
\hline Gender & .080 & .088 & .089 & .080 & .079 & .080 & .080 & .090 & .091 \\
\hline Age & -.152 & -.164 & -.166 & -.152 & -.146 & -.147 & -.152 & -.152 & -.154 \\
\hline $\begin{array}{l}\text { Length of service in the } \\
\text { enterprise }\end{array}$ & .147 & .157 & .156 & .147 & .160 & .162 & .147 & .162 & .163 \\
\hline In the current working time & .108 & .109 & .108 & .108 & .094 & .092 & .108 & .091 & .090 \\
\hline The level of education & -.022 & -.007 & -.004 & -.022 & -.016 & -.015 & -.022 & -.011 & -.009 \\
\hline $\begin{array}{l}\text { 2. The main effect } \\
\text { OL }\end{array}$ & & $.369^{* *}$ & $.430^{* \pi}$ & & & & & & \\
\hline EA & & & & & $.398^{* *}$ & $.361^{* *}$ & & & \\
\hline SSG & & & & & & & & $.310^{*}$ & $.208^{*}$ \\
\hline $\mathrm{PP}$ & & $.299^{*}$ & $.256^{*}$ & & $.181^{*}$ & $.180^{*}$ & & $.163^{*}$ & $.150^{*}$ \\
\hline 3. interaction & & & & & & & & & \\
\hline $\mathrm{OL} * \mathrm{PP}$ & & & $.134^{*}$ & & & & & & \\
\hline EA*PP & & & & & & $.082^{*}$ & & & \\
\hline SSG*PP & & & & & & & & & $.048^{*}$ \\
\hline $\mathrm{R}^{2}$ & .129 & .319 & .254 & .129 & .343 & .287 & .129 & .289 & .225 \\
\hline$\Delta \mathrm{R}^{2}$ & .103 & $.259^{* \pi}$ & $.237^{*}$ & .103 & $.336^{*}$ & $.253^{*}$ & .103 & $.231^{*}$ & $.216^{*}$ \\
\hline F value & $1.890^{*}$ & $9.688^{* *}$ & $11.340^{* \pi}$ & $1.890^{*}$ & $10.429^{* \pi}$ & $8.125^{* \pi}$ & $1.890^{*}$ & $6.844^{* \pi}$ & $4.230^{* \pi}$ \\
\hline
\end{tabular}

Notes: $(1)^{* *} p<0.05$, * $p<0.1$, two-tailed test. (2) "OL" means " obedience leadership ", "EA" means " emotional attachment ", and " JP " means "job performance", "PP” means" proactive personality”. 


\section{Conclusions and Discussion}

Based on the verification of the relationship between deference to supervisor, affective attachment, personal-life inclusion of SSG and job performance via the surveys of 327 employees, the study further discusses the moderation effect of proactive personality. The study finds that deference to supervisor, affective attachment and the overall SSG variables have significant positive effect on job performance, and personal-life inclusion have no significant effect on job performance, which proves the SSG is harmonious in the respondents`enterprises. And the construction of SSG pays more attention on the deference to supervisor and affective attachment dimensions, rather than the participation degree of the leaders' private life. Moreover, the study finds that proactive personality has a significant positive moderating effect on the relationship between deference to supervisor, affective attachment, personal-life inclusion of SSG and job performance. Besides, proactive personality has no significant moderating effect on the relationship between personal involvement and job performance.

The study also has some limitations, which is the direction of the further research. First, the study is based on the enterprises of Shaanxi province to obtain the first-hand data, however considering the dissimilarity of various regions, workplaces and positions, there is a need to further discuss the universality of regions, workplaces and positions in different areas. Second, the sample scale should be chose appropriately by considering the actual situation for the future research, or develop a SSG scale which is suited to Chinese situation to obtain more accurate and high-quality data.

\section{References}

1. D.Tjosvold, Power and social context in superior-subordinate interaction, J. Organizational Behavior and Human Decision Processes. 3 (1985) 281-293.

2. T. S.Bateman, J. M.Crant, The proactive component of organizational behavior: A measure and correlates, J. Journal of Organizational Behavior. 14 (1993) 103 118.

3. M. Liu, L.Long, W.Zu, A Review of Proactive Personality, J. Advances in Psychological Science. 2 (2007) 333-337.

4. X.Guo, Reviews on the Research of Supervisor-subordinate Relationship in Chinese Context: Leader-Member Exchange and Supervisor-Subordinate Guanxi, J. Nankai Business Review. 2 (2011) 61-68.

5. X.Guo, C. Li, Supervisor-Subordinate Guanxi in China: An Integrative Construct and the Preliminary Examination, J. Chinese Journal of Management. 2 (2015) 167-177.

6. Y.Chen, R. Friedman, E.Yu, et al, Supervisor-Subordinate Guanxi: Developing a Three-Dimensional Model and Scale, J. Management and Organization Review. 5 (2009) 375 399.

7. W.C.Borman, S. J. N Motowidlo, Expanding the criterion domain to include elements of contextual performance in personnel selection in organizations. Jossey-Bass, San 
Francisco, 1993, str. 71-98.

8. E. R.Greenglass, Work rage and its psychological implications. Invited paper presented at the 21th International STAR Conference, Bratislava, Slovakia, 2000, July:20-22.

9. J.A. Thompson, Proactive Personality and Job Performance: A Social Capital Perspective, J. Journal of Applied Psychology. 90 (2005) 1011-1017. 